ARTICLE

Received 24 Feb 2016 | Accepted 25 Apr 2016 | Published 13 Jun $2016 \quad$ DOl: 10.1038/ncomms11730 OPEN

\title{
Long noncoding RNA NRON contributes to HIV-1 latency by specifically inducing tat protein degradation
}

Jun $\mathrm{Li}^{1,2}$, Cancan Chen ${ }^{1,2, \star}$, Xiancai Ma ${ }^{1,2,}$, Guannan Geng ${ }^{1,2}$, Bingfeng Liu,2, Yijun Zhang ${ }^{1,2}$, Shaoyang Zhang ${ }^{1,2}$, Fudi Zhong ${ }^{1,2}$, Chao Liu'1,2, Yue Yin ${ }^{1,2}$, Weiping Cai ${ }^{3} \&$ Hui Zhang ${ }^{1,2}$

Long noncoding RNAs (IncRNAs) play multiple key regulatory roles in various cellular pathways. However, their functions in HIV-1 latent infection remain largely unknown. Here we show that a IncRNA named NRON, which is highly expressed in resting CD4 ${ }^{+}$ $T$ lymphocytes, could be involved in HIV-1 latency by specifically inducing Tat protein degradation. Our results suggest that NRON IncRNA potently suppresses the viral transcription by decreasing the cellular abundance of viral transactivator protein Tat. NRON directly links Tat to the ubiquitin/proteasome components including CUL4B and PSMD11, thus facilitating Tat degradation. Depletion of NRON, especially in combination with a histone deacetylase (HDAC) inhibitor, significantly reactivates the viral production from the HIV-1-latently infected primary $\mathrm{CD}^{+}{ }^{+} \mathrm{T}$ lymphocytes. Our data indicate that IncRNAs play a role in HIV-1 latency and their manipulation could be a novel approach for developing latency-reversing agents.

\footnotetext{
${ }^{1}$ Institute of Human Virology, Zhongshan School of Medicine, Sun Yat-sen University, Guangzhou, Guangdong 510080, China. ${ }^{2}$ Key Laboratory of Tropical Disease Control of Ministry of Education, Zhongshan School of Medicine, Sun Yat-sen University, Guangzhou, Guangdong 510080, China. ${ }^{3}$ Department of Infectious Diseases, Guangzhou 8th People's Hospital, Guangzhou, Guangdong 510060, China. * These authors contributed equally to this work.

Correspondence and requests for materials should be addressed to H.Z. (email: zhangh92@mail.sysu.edu.cn.).
} 
$\mathrm{n}$ recent years, tens of thousands of human long noncoding RNAs (lncRNAs) have been annotated by genome-wide signature analysis or multiple deep-sequencing technology ${ }^{1-3}$. With increased reports suggesting their functionality, it has been realized that lncRNAs are more than transactional 'noise"4. LncRNAs can bind to various proteins, DNAs or RNAs to form functional complexes 5,6 , and participate in multiple cellular processes including epigenetic modification ${ }^{7-10}$, transcriptional $^{11,12}$ and post-transcriptional regulation ${ }^{13-16}$ of gene expression, signal transduction ${ }^{17}$, transportation ${ }^{18}$ and many others ${ }^{19}$. LncRNAs have been implicated in differential physiological and pathological processes, such as stemness maintenance ${ }^{20}$, organ development $^{13}$, cancer progression ${ }^{9}$, immune regulation ${ }^{21}$ and pathogen infection ${ }^{22,23}$.

HIV-1 latent infection in resting $\mathrm{CD} 4{ }^{+} \mathrm{T}$ lymphocytes is the major obstacle to eradicate the virus in patients after suppressive combination antiretroviral therapy (cART) ${ }^{24-26}$. Because of its presence, the life-long cART is required, otherwise the viremia will rapidly rebound. HIV-1 latency could be due to deficiency of transcriptional factors such as nuclear factor-kappa B (NF-kB) or nuclear factor of activated T-cells (NFAT) ${ }^{27,28}$, lack of the viral accessory protein $\mathrm{Tat}^{29}$ or condensed chromatin structure and epigenetic regulation ${ }^{30-33}$. In addition, a cluster of microRNAs including miR-28, miR-125b, miR-150, miR-223 and miR-382, which are enriched in resting $\mathrm{CD}_{4}^{+}$ $\mathrm{T}$ lymphocytes, target the $3^{\prime}$-untranslated repeat of HIV-1 mRNA to restrict viral gene expression, and subsequently contribute to HIV-1 latency ${ }^{34}$.

Here we investigated the role of lncRNAs in HIV-1 latent infection, and have identified a lncRNA NRON, which potentially contributes to HIV-1 latent infection. NRON RNA significantly inhibits the HIV-1 promoter activity and decreased the cellular abundance of viral transactivator protein Tat. Further mechanism studies suggest that Tat protein is linked to the ubiquitin/ proteasome components CUL4B and PSMD11 by NRON, and then degraded. Depletion of NRON RNA, especially in combination with a latency-reverse agent SAHA, robustly reactivated the latently infected proviruses both in an in vitro latency model and primary resting $\mathrm{CD} 4{ }^{+} \mathrm{T}$ lymphocytes isolated from infected individuals receiving suppressive cART. Our data indicated that NRON plays a role in HIV-1 latency maintenance, and it could be a new target for reversing viral latency.

\section{Results}

LncRNA NRON represses HIV-1 replication. To determine whether any lncRNA was involved in HIV-1 replication and latency, we selected several lncRNAs that were previously reported to be highly expressed in human immune system including the thymus ${ }^{18}$, lymph nodes and white blood cells ${ }^{35}$, and examined their expression in human primary $\mathrm{CD}^{+}$ $\mathrm{T}$ lymphocytes with real-time quantitative reverse transcriptasePCR (qRT-PCR). Some lncRNAs were highly expressed in comparison with the mRNA level of the control gene T-bet, which was reported to be expressed in CD ${ }^{+} \mathrm{T}_{\text {lymphocytes }}{ }^{36}$ (Fig. 1a). A few of the abundant lncRNAs showed significantly higher expression levels in resting $\mathrm{CD}^{+}{ }^{+} \mathrm{T}$ lymphocytes than those in activated cells (Fig. 1b). On screening with a group of lncRNAspecific short interfering RNA (siRNA) pools of two or three siRNAs for one target lncRNA to reduce off-target effects, we found that several lncRNAs including NRON and TUG1 affected the replication of HIV-1 (Fig. 1c and Supplementary Fig. 1). The depletion of NRON, which exerted a definitely higher expression level in resting $\mathrm{CD} 4{ }^{+} \mathrm{T}$ lymphocytes through Northern blotting detection (Fig. 1d), significantly enhanced the viral replication in a time-course study (Fig. 1e).
NRON specifically represses $\mathrm{HIV}-1$ transcription. To investigate which stage of HIV-1 replication was likely affected by NRON, we employed the defective HIV-1 provirus plasmid pNL4-3-deltaEEGFP for transfection assay in HEK293T cells ${ }^{37}$, which also express endogenous NRON RNA at a high level (Supplementary Fig. 2a). The intracellular Gag proteins expression obviously increased when NRON was depleted by siRNAs (Fig. 2a). Conversely, Gag proteins expression decreased when NRON was overexpressed in HeLa cells, which showed a low expression level of endogenous NRON (Supplementary Fig. 2a). Furthermore, the expression level of HIV1 total mRNA in HEK293T cells showed a significant increase when NRON was knocked down (Fig. 2b), implying that the viral transcription or viral RNA stability could be affected by NRON. As many lncRNAs can regulate gene transcription, we employed a reporter luciferase system for HIV-1 promoter activity to examine whether NRON affected HIV-1 transcription. The HIV-1 promoter activity significantly increased after NRON was depleted in HEK293T cells (Fig. 2c), and was greatly reduced when NRON was overexpressed in TZM-bl cells, which also showed a low expression level of endogenous NRON (Supplementary Fig. 2a,c). To determine whether NRON suppressed the transcription of other viral promoters, we employed reporter luciferase systems for cytomegalovirus (CMV), Moloney murine leukemia virus (MMLV) and Rous sarcoma virus (RSV) promoters. Only slight changes were observed in these promoter reporter systems when NRON was knocked down (Supplementary Fig. 2d-f), indicating that NRON could specifically suppress HIV-1 promoter activity.

NRON induces Tat protein degradation. On the basis of the above observations, we next sought to identify the targeting site(s) of NRON on HIV-1 promoter. NRON has been reported as a negative regulator of NFAT signalling pathway ${ }^{18}$. As HIV-1 harbours two sets of canonical NFAT-binding site in its $5^{\prime}$ long terminal repeat (LTR), which can enhance the viral transcription $^{38-40}$, we constructed a HIV-1 promoter reporter plasmid with mutations at both these sites. Dual-luciferase reporter assay showed that the activity of NFAT-binding site-mutated HIV-1 promoter still increased on the knockdown of NRON in HEK293T cells (Supplementary Fig. 3a). Further, it has been shown that NFAT signal activity in HEK293T cells was relatively weak without stimulation by phorbol myristate acetate/ ionomycin ${ }^{18}$, which is consistent with latently infected resting $\mathrm{CD} 4{ }^{+} \mathrm{T}$ lymphocytes. Therefore, our data indicated that NRON could regulate HIV-1 transcription through a NFAT-independent pathway in our HEK293T cell line monitor system.

The intact HIV-1 $5^{\prime}$ LTR promoter contains four functional regions, namely the modulatory region $(-454$ to -105 nucleotide (nt) relative to the transcription start site), the enhancer region $(-104$ to $-79 \mathrm{nt})$, the basal promoter $(-78$ to $-1 \mathrm{nt})$ and TAR element $(+1 \text { to }+60 \mathrm{nt})^{41}$. We constructed mutated HIV-1 promoters with deletions of the modulatory region and the enhancer region, or the TAR element (Supplementary Table 1). Although the promoter activity was significantly decreased because of these mutations, the core HIV-1 promoter with only the basal promoter and the TAR element could still be regulated by NRON (Supplementary Fig. 3b). However, the TAR element-deficient promoter did not exhibit this feature on modification (Supplementary Fig. 3c). It is well known that the TAR element recruits Tat, which then exploits CDK9 and Cyclin-T1 and plays a key role in transcription elongation ${ }^{42-44}$. The specific U-residue-rich bulge $(+23$ to $+25 \mathrm{nt})$ in the stem of TAR RNA is required for Tat binding, and mutation of the $U$ residues in the bulge will significantly reduce its affinity to Tat ${ }^{45-47}$. When we substituted the $U$ residues in the bulge with $G$ residues in the TAR region to 

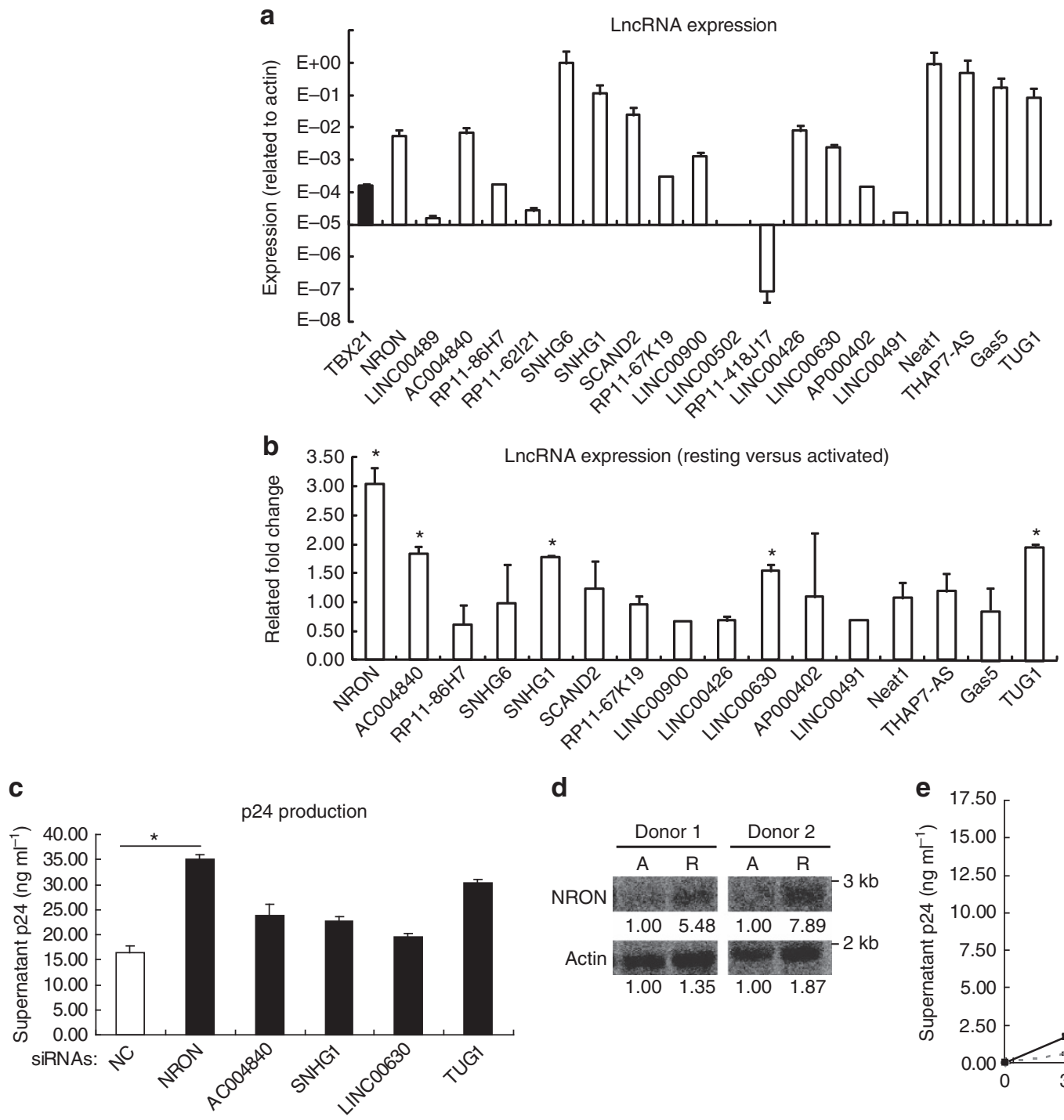

d

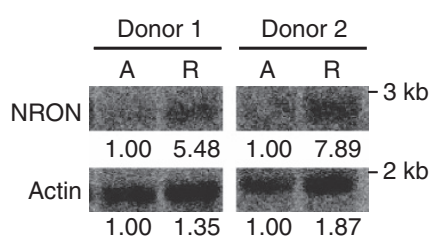

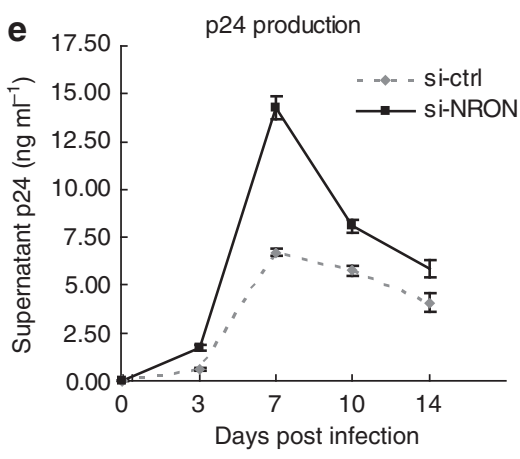

Figure 1 | LncRNA NRON represses HIV-1 replication. (a) The expression levels of IncRNAs in activated primary $C D 4^{+} \mathrm{T}$ lymphocytes were detected with real-time qRT-PCR. The expression of T-bet was detected as positive control $(n=3)$. (b) Real-time qRT-PCR detection of the IncRNAs expression level differences between the resting and activated primary CD4 ${ }^{+}$T lymphocytes from a same donor $(n=3)$. (c) The activated primary CD4 ${ }^{+}$T lymphocytes

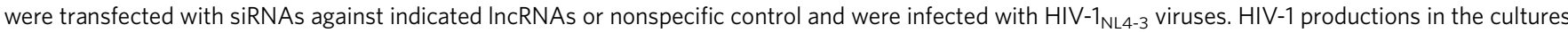
were detected by p24 ELISA at 7 days post infection $(n=3)$. (d) Northern blotting detection of NRON expression in the resting $(R)$ or activated $(A)$ primary $\mathrm{CD}_{4}^{+} \mathrm{T}$ lymphocytes from the same donors. Numbers indicated the fold change related to control. (e) The activated primary $\mathrm{CD} 4{ }^{+} \mathrm{T}$

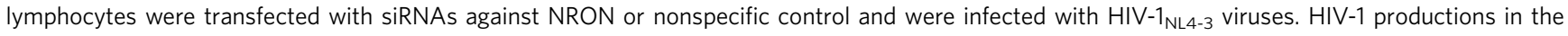
cultures were detected with p24 ELISA at indicated time points post infection $(n=3)$. The results in $\mathbf{a}-\mathbf{c}, \mathbf{e}$ show mean \pm s.d. (error bars). ${ }^{\star} P<0.05$, Student's unpaired $t$-test.

disrupt the Tat-TAR interaction, dual-luciferase assay showed that the mutated promoter was no longer affected by NRON knockdown (Supplementary Fig. 3d). We then investigated whether NRON was still functional in the absence of Tat. We indeed found that, in the absence of Tat-expressing plasmid, the regulation of NRON on $\mathrm{HIV}-1$ promoter activity was no longer significant (Supplementary Fig. 3e). All these data indicated that the Tat-TAR axis was involved in NRON function.

Since Tat is a RNA-binding protein, we initially hypothesized that NRON could bind to Tat protein and disrupt its recruitment to TAR RNA, thus functioning as a competing endogenous RNA ${ }^{14}$. RNA co-immunoprecipitation (RNA co-IP, RIP) and real-time qRT-PCR data showed that the enrichment of NRON by Tat was more than 15-fold increase compared with the green fluorescent protein (GFP) control in NRON-overexpressed TZM-bl cells (Fig. 2d). In addition, Tat could also potently enrich the endogenously expressed NRON in HEK293T cells (Supplementary Fig. 4a), indicating that Tat binds to NRON in an HIV-1 promoter-independent manner. We then confirmed that the association between Tat and TAR-Luc RNA reduced on NRON overexpression in TZM-bl cells (Fig. 2e). Unexpectedly and interestingly, Tat protein abundance, initially detected as the input control by western blotting for RNA co-IP assay, significantly decreased on NRON overexpression in TZM-bl cells (Fig. 2e), while the Tat mRNA level remained unchanged (Supplementary Fig. 4b). Conversely, when NRON was depleted in HEK293T cells, the Tat protein level increased. However, the control GFP protein level showed no significant changes (Fig. 2f). Meanwhile, knockdown of NRON RNA did not affect the protein level of other HIV-1 proteins, such as Nef and Vpr (Supplementary Fig. 4c). Collectively, these data suggested that NRON RNA specifically induced the reduction of Tat at the protein level. 
NRON forms a complex with CUL4B and PSMD11. Because of the findings thus far, we started to notice that three of the reported NRON-binding proteins, CUL4B, PSMD11 and HUWE1 (UREB1), belong to the ubiquitin/proteasome system ${ }^{18}$. We speculated that these proteins were involved in the process of NRON-mediated Tat degradation. To examine this hypothesis, we first investigated the roles of these proteins in HIV-1 transcription by a loss-of-function assay (Supplementary Fig. 4d). The transcription repression of HIV-1 promoter by NRON overexpression in TZM-bl cells was counteracted by CLU4B or PSMD11 knockdown, but not by HUWE1 (Fig. 3a). Correspondingly, the depletion of these proteins remarkably reversed Tat reduction caused by NRON overexpression in TZMbl cells (Fig. 3b). Meanwhile, NRON RNA could be enriched by CUL4B (Fig. 3c) or PSMD11 (Fig. 3d), indicating that they were associated with NRON RNA robustly. Further, we found that Tat interacted with CUL4B or PSMD11 by co-IP; however, the interaction significantly decreased in the presence of RNase A (Supplementary Fig. 4e). When NRON was knocked down in the HEK293T cells, the interactions between Tat and CUL4B or

a

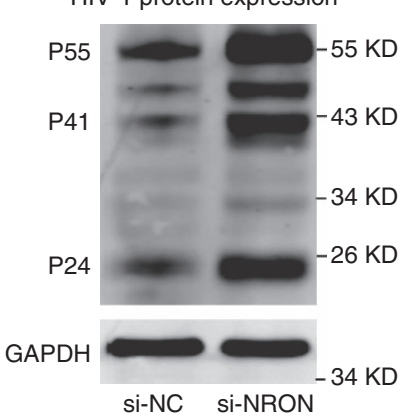

C

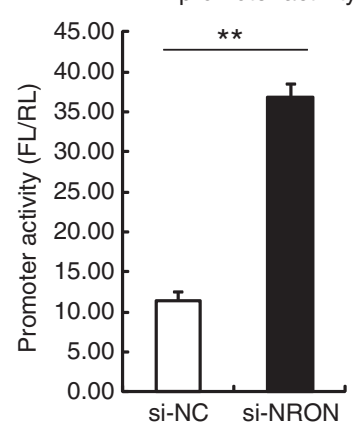

e

TAR RNA enrichment by Tat
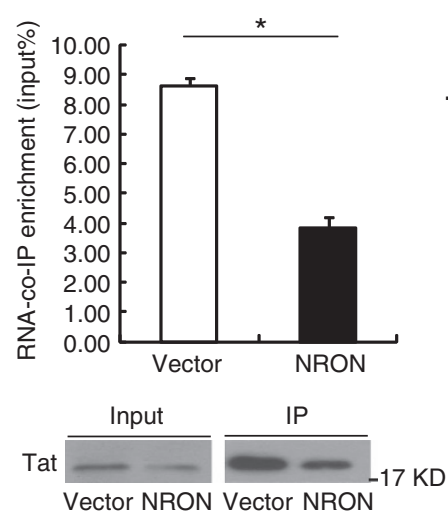

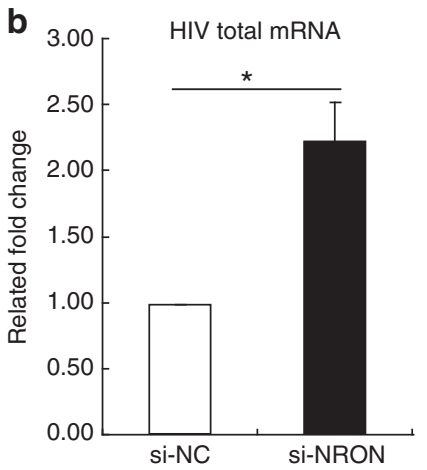

d
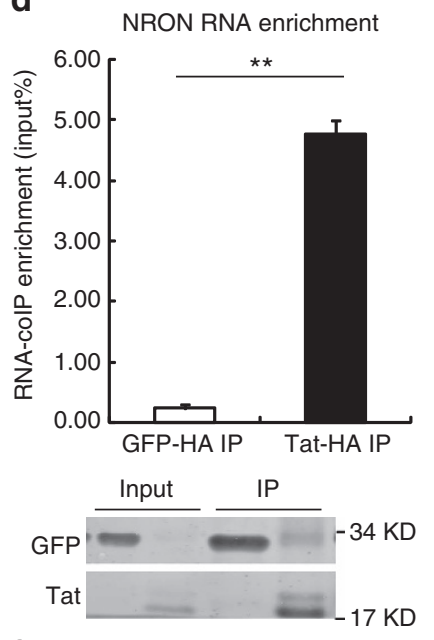

$\mathbf{f}$

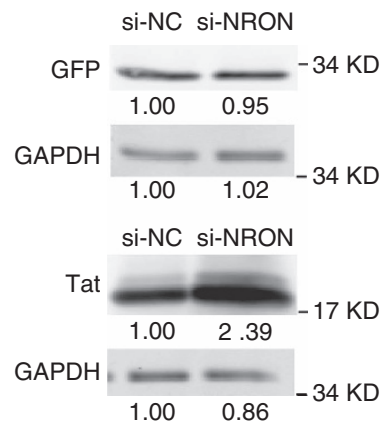

PSMD11 were significantly diminished (Supplementary Fig. 4f). Moreover, the in vitro ubiquitination assay and the subsequent western blotting detection showed that Tat ubiquitination was significantly decreased when NRON was depleted (Fig. 3e). The same result was observed when CUL4B or PSMD11 was knocked down (Fig. 3f). Collectively, these data suggested that NRON mediated Tat degradation by bridging Tat and the components of ubiquitin/proteasome, and by facilitating the ubiquitination of Tat protein.

NRON participates in maintaining HIV-1 latency. Since NRON showed higher expression level in resting $\mathrm{CD} 4{ }^{+} \mathrm{T}$ lymphocytes than in activated cells, we sought to determine whether this lncRNA functions in HIV-1 latent infection. Initially, we confirmed whether NRON could regulate HIV-1 transcription in primary resting $\mathrm{CD}^{+}{ }^{+} \mathrm{T}$ lymphocytes. HIV -1 promoter reporter system plasmids, Tat-expressing plasmids, control siRNA or NRON siRNA were nucleofected into resting $\mathrm{CD} 4{ }^{+} \mathrm{T}$ lymphocytes by electroporation. Dual-luciferase reporter assay showed that the activity of HIV-1 promoter significantly increased on NRON knockdown (Fig. 4a), which suggested that NRON RNA suppressed HIV-1 transcription in resting CD4 ${ }^{+}$T lymphocytes. We then examined the effect on Tat protein in resting NRON-depleted CD4 ${ }^{+}$T lymphocytes. Western blotting showed that the Tat protein level significantly increased on NRON knockdown (Fig. 4b). These data indicated that NRON RNA could suppress HIV-1 transcription by inducing Tat protein degradation in resting $\mathrm{CD}^{+}{ }^{+} \mathrm{T}$ lymphocytes, which were the major population of HIV-1-latently infected cells.

Further, we generated a modified primary $\mathrm{CD}_{4}^{+}$ $\mathrm{T}$ lymphocyte-based latency model ${ }^{48,49}$. A $b c l-2$ open reading frame (ORF) was properly inserted into the nef ORF in the defective HIV-1 provirus plasmid pNL4-3-deltaE-EGFP to express Bcl-2 protein for promoting cell survival (Supplementary Fig. 5a,b). The resulting HIV/VSV (vesicular stomatitis virus)pseudotyped viruses were used to infect the activated human primary $\mathrm{CD}^{+}{ }^{+} \mathrm{T}$ lymphocytes. The GFP + cells were enriched and expanded, and then cultured for $\sim 1$ month to allow the cells to convert to resting status (Supplementary Fig. 5d,e). When we transfected the cells with NRON-specific siRNAs, the viruses in the latently infected cells were significantly reactivated (Fig. 4c,d

Figure 2 | NRON represses HIV-1 transcription by inducing Tat degradation. (a) HEK293T cells were co-transfected with pNL4-3-deltaEEGFP provirus plasmid and siRNAs against NRON or nonspecific control. Gag proteins expression was determined by western blotting with anti-p24 antibody at $72 \mathrm{~h}$ after transfection. (b) Total HIV-1 mRNAs including spliced and unspliced mRNAs were detected with real-time GRT-PCR in the same HEK293T cells described in a $(n=3)$. (c) HEK293T cells were co-transfected with pHIV-Pro-Luc reporter plasmids, pcDNA3.1-Tat-HA, pRL-CMV (as a transfection normalization reporter) and siRNAs against NRON or nonspecific control. The promoter activity was determined by dual-luciferase reporter assay at $48 \mathrm{~h}$ after transfection $(n=3)$.

(d) Overexpressed NRON RNA was co-immunoprecipitated by HA-tagged Tat in TZM-bl cells, and the enriched RNA was determined by real-time qRT-PCR. RNA co-immunoprecipitated by HA-tagged GFP was set as a control $(n=3)$, and the precipitated proteins were detected by western blotting. (e) The pcDNA3.1-NRON or empty vector was co-transfected with pcDNA3.1-Tat-HA into TZM-bl cells, the TAR-Luc RNA was enriched by RNA co-immunoprecipitation with anti-HA agarose and quantified with real-time qRT-PCR $(n=3)$. The precipitated proteins were detected by western blotting. (f) Tat and control GFP were detected by western blotting on NRON knockdown in HEK293T cells. Numbers indicated the fold change related to control. Data in $\mathbf{b}$-e show mean \pm s.d. (error bars). Results in a,f represent three independent experiments. ${ }^{\star} P<0.05,{ }^{\star \star} P<0.01$, Student's unpaired $t$-test. 
a

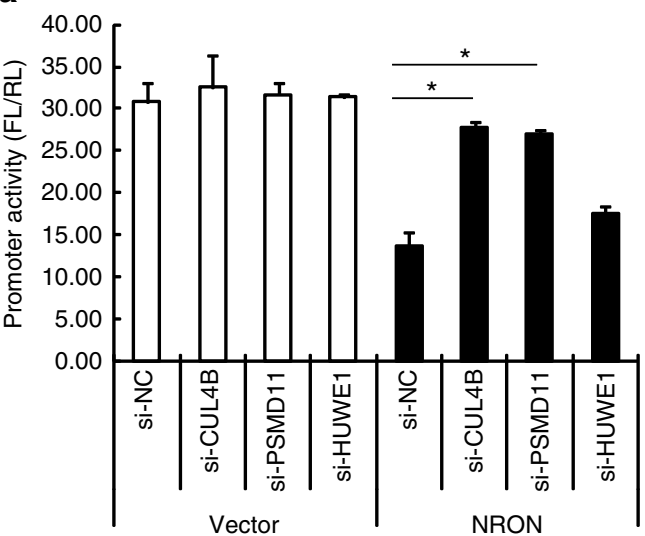

b

Expression Vector NRON NRON NRON NRON

SiRNA $\quad-\quad N C \quad$ CUL4B PSMD11

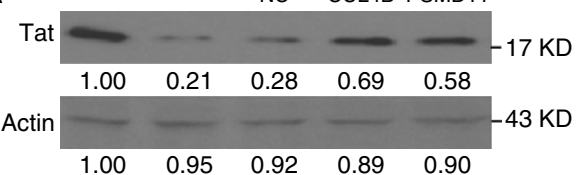

C

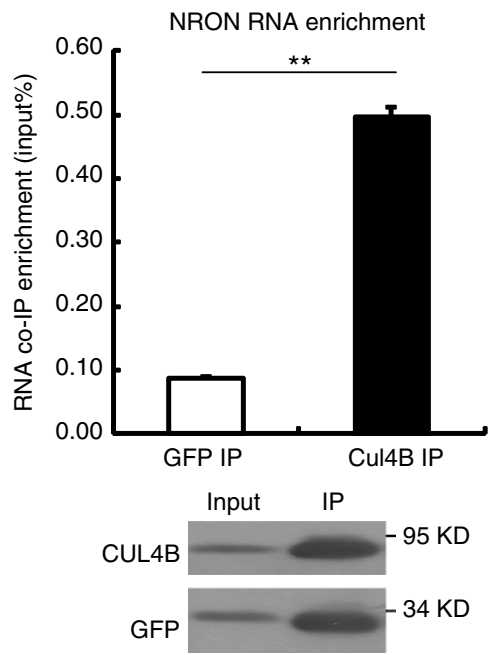

d

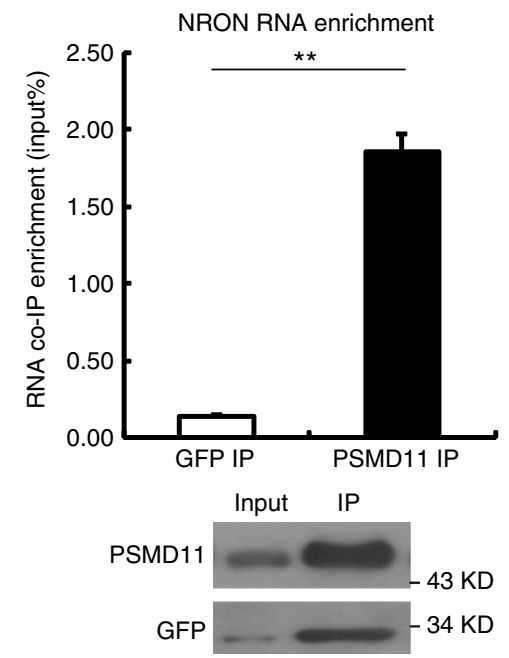

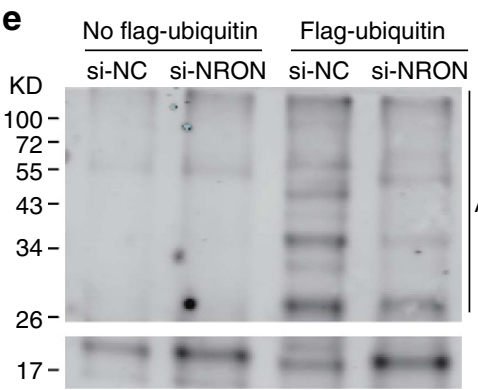

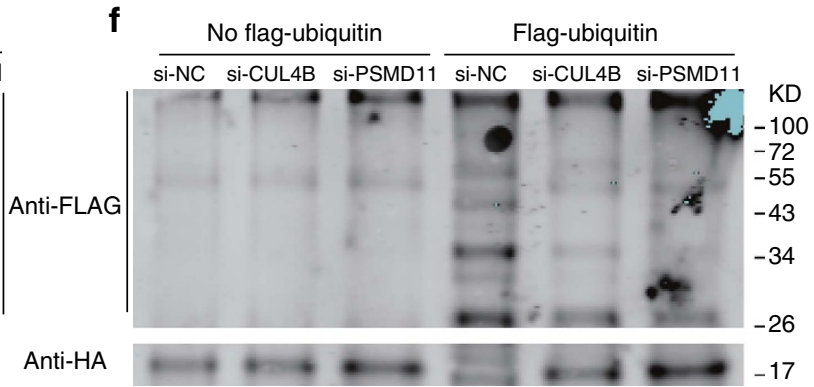

Figure 3 | NRON conjugates Tat protein to the ubiquitin/proteasome system and induces its ubiquitination. (a) The indicated siRNAs were

co-transfected with HIV-1 promoter reporter plasmids into HEK293T cells, and the promoter activities were measured with dual-luciferase reporter assay $(n=3)$. (b) siRNAs against CUL4B and PSDM11 were co-transfected with pcDNA3.1-Tat-HA and pcDNA3.1-NRON into TZM-bl cells, and the Tat protein levels were detected by western blotting at $48 \mathrm{~h}$ post transfection. Numbers indicated the fold change related to control. The endogenous NRON RNA in HEK293T cells was co-immunoprecipitated by ectopically expressed FLAG-tagged CUL4B (c) or PSMD11 (d) and was quantified using real-time qRT-PCR $(n=3)$. In vitro ubiquitination assay was performed, and western blotting showed the ubiquitin-labelled Tat when NRON (e), CUL4B or PSMD11 (f) was knocked down. Data in $\mathbf{a}, \mathbf{c}, \mathbf{d}$ show mean \pm s.d. (error bars). Results in $\mathbf{b}, \mathbf{e}, \mathbf{f}$ represent three independent experiments. ${ }^{\star} P<0.05$, ${ }^{\star \star} P<0.01$, Student's unpaired $t$-test.

and Supplementary Fig. 5f). Furthermore, after transfection with NRON-specific siRNAs supplemented with the treatment of suberoylanilide hydroxamic acid (SAHA), a well-known histone deacetylase (HDAC) inhibitor and latency-reversing agent $(\mathrm{LRA})^{50}$, the reactivation level was much higher than that treated with nonspecific siRNA in combination with SAHA (Fig. 4c,d). Moreover, we examined the effect of knockdown of NRON upon HIV-1 latency in resting $\mathrm{CD} 4^{+} \mathrm{T}$ lymphocytes directly isolated from HIV-1-infected individuals receiving suppressive cART. Alu-PCR was employed to confirm that the cells harboured proviral HIV-1 DNA (Supplementary Fig. 5g) ${ }^{34}$. After transfection of the resting cells with NRON-specific siRNAs in combination with SAHA treatment, the virion-associated RNA in the culture supernatant was significantly higher than that treated with nonspecific siRNA in combination with SAHA (Fig. 4e and Supplementary Fig. 5h). No significant change was observed by NRON knockdown only (Supplementary Fig. 5i), which may be because of the fact that the proviruses were 
a

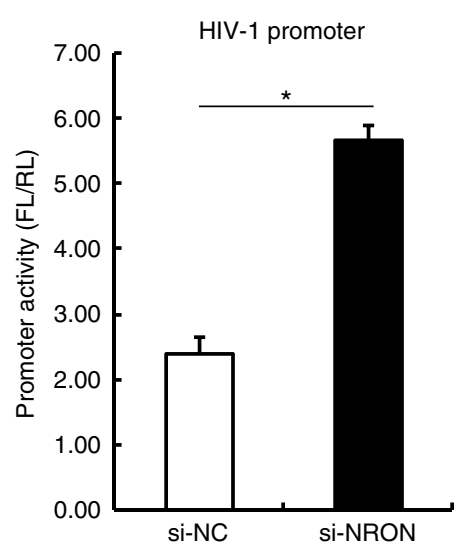

d

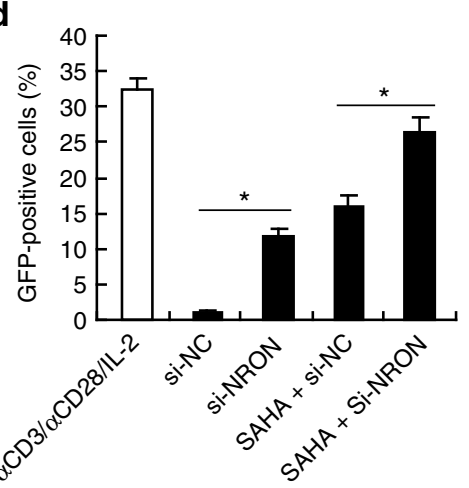

e
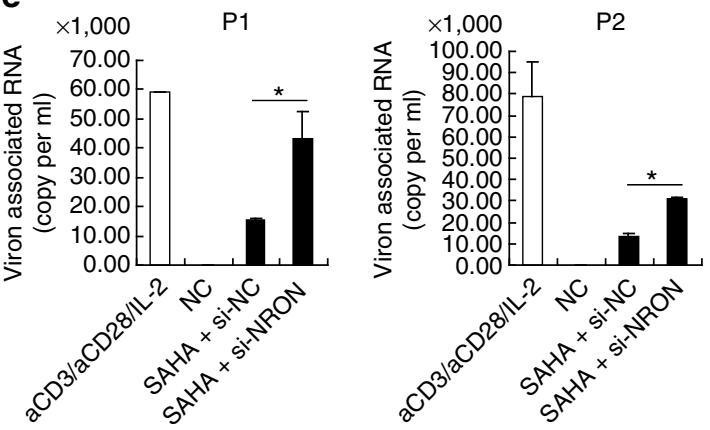
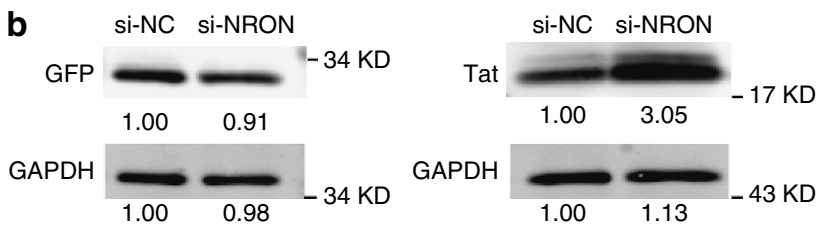

C
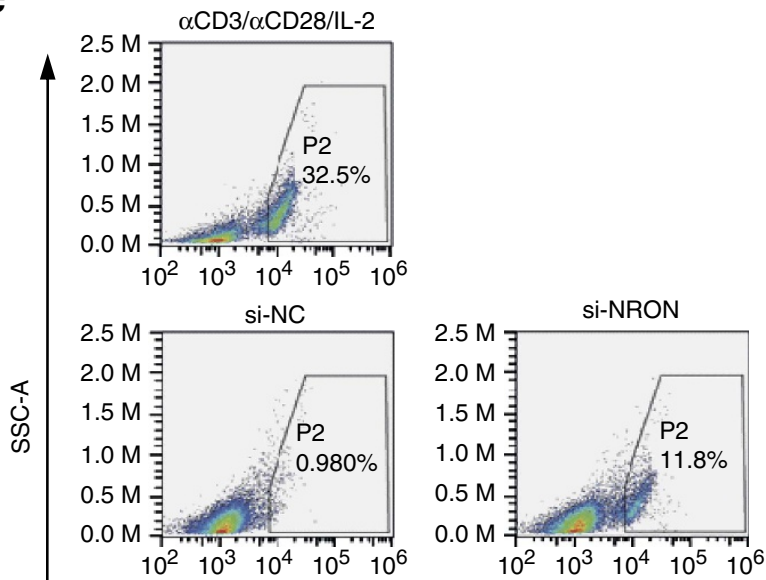

$\mathrm{SAHA}+\mathrm{Si}-\mathrm{NC}$

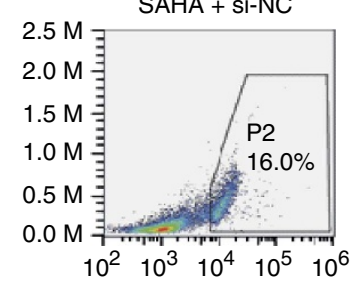

SAHA + Si-NRON

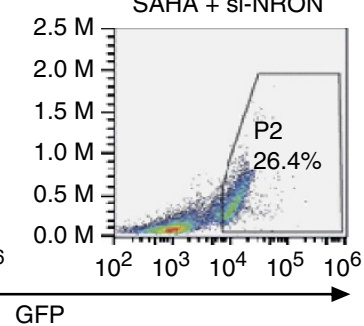

f Corelation between HIV-1 gene
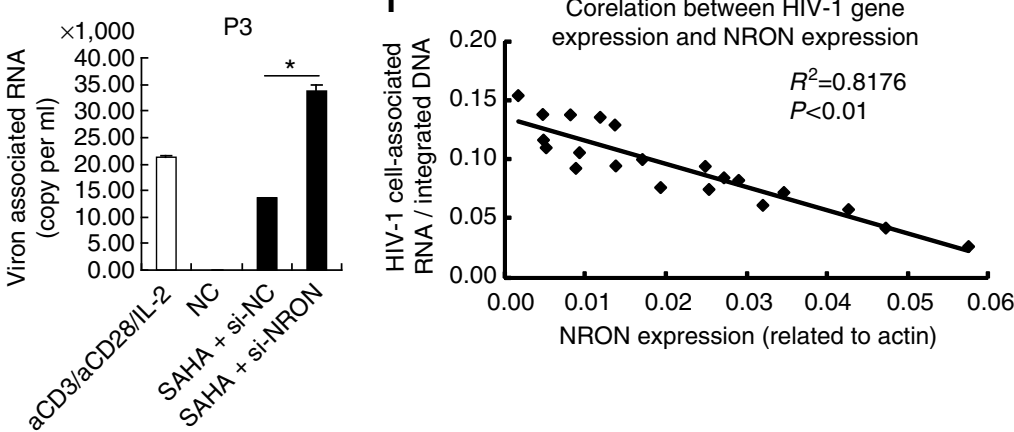

Figure 4 | Depletion of NRON reactivates HIV-1 viruses in latently infected CD4 ${ }^{+} \mathbf{T}$ lymphocytes. (a) Primary resting CD4 ${ }^{+} \mathrm{T}$ lymphocytes were nucleofected with HIV-1 promoter reporter system plasmids, pcDNA3.1-Tat-HA and siRNAs against NRON or nonspecific control. The promoter activity was determined with dual-luciferase reporter assay at $48 \mathrm{~h}$ after transfection $(n=3)$. (b) Tat and control GFP were detected by western blotting on NRON knockdown in nucleofected primary resting $\mathrm{CD}_{4}{ }^{+} \mathrm{T}$ lymphocytes. Numbers indicated the fold change related to the control. (c) The latently infected cells were transfected with NRON siRNAs or nonspecific control, or were transfected with siRNAs in combination with the treatment of SAHA, and detected by FACS at $48-72 \mathrm{~h}$ post transfection. The GFP + ratio indicated the reactivation level $(\mathbf{d} ; n=3)$. (e) Resting CD4 ${ }^{+}$T lymphocytes isolated from HIV-1-infected individuals on suppressive CART were transfected with siRNAs in combination with the treatment of SAHA. After $48 \mathrm{~h}$, HIV-1 virion-associated RNAs in the supernatants were isolated and detected with real-time qRT-PCR $(n=3)$. (f) The intracellular HIV-1 RNA and NRON RNA expression levels were detected in resting CD4 ${ }^{+}$T lymphocytes isolated from HIV-1-infected individuals on suppressive cART ( $n=20$ ), and the correlation between the HIV-1 RNA and NRON RNA levels was shown. The simple linear regression analysis was performed and linear regression line was shown. Data in $\mathbf{a}, \mathbf{d}, \mathbf{e}$ show mean \pm s.d. (error bars). Results in $\mathbf{b}$ represent three independent experiments. ${ }^{\star} P<0.05$, Student's unpaired $t$-test.

more difficult to be reactivated from the primary resting $\mathrm{CD}^{+} \mathrm{T}$ lymphocyte directly isolated from HIV-1-infected individuals receiving suppressive cART than that from the HIV-1-latently infected primary $\mathrm{CD}^{+}{ }^{+} \mathrm{T}$ lymphocytes, which were experimentally generated.

We then directly isolated resting $\mathrm{CD} 4{ }^{+} \mathrm{T}$ lymphocytes from $\mathrm{HIV}$-1-infected individuals receiving suppressive cART, and detected the intracellular HIV-1 proviral DNA, the expression level of HIV-1 RNA and NRON RNA. We found that the intracellular HIV-1 RNA expression, after being normalized with the cell-associated viral DNA, was inversely correlated with the NRON RNA expression level (Fig. 4f). Collectively, these data indicated that NRON contributed to HIV-1-latent infection. The abundance of NRON in resting $\mathrm{CD} 4{ }^{+} \mathrm{T}$ lymphocytes efficiently 
blocks the expression of viral proteins and could, therefore, allow the infected cells to evade from the immune surveillance in vivo.

\section{Discussion}

Because of their essential regulatory roles in various cellular molecular networks, it is easy to understand why lncRNAs have been implicated in viral infection and immune regulation. A recent report showed that the IncRNA NEAT1 possessed an unspecific effect on the exporting of many mRNAs including HIV-1 RNA ${ }^{51}$. The NRON IncRNA was previously implicated in the severity of inflammatory bowel disease through its inhibitory effects on NFAT signalling ${ }^{18,52}$. As HIV-1 harbours NFATbinding sites in its $5^{\prime}$ LTR promoter region ${ }^{38-40}$, it is highly likely that NRON may suppress HIV-1 replication in activated primary $\mathrm{CD} 4{ }^{+} \mathrm{T}$ lymphocytes through inhibiting NFAT signal, which was described in a recent report by others ${ }^{33}$. However, in latently infected resting $\mathrm{CD}^{+}{ }^{+} \mathrm{T}$ lymphocytes, NFAT signal activity is relatively weak without stimulation, which is consistent with our HEK293T and HeLa cell line monitor system ${ }^{18,28}$. In these systems, the mutation of NFAT-binding sites in the promoter did not affect the inhibitory effect of NRON on HIV-1 transcription (Supplementary Fig. 3a). In addition, knockdown of NRON could significantly enhance the viral production from latently infected resting $\mathrm{CD}^{+}{ }^{+} \mathrm{T}$ lymphocytes without reactivating the cells (Fig. 4). These data support our hypothesis that NRON RNA could potently inhibit HIV-1 transcription and play a role in maintaining HIV-1 latency in an NFAT-independent mechanism in resting cells.

Our work further indicates that, by forming a complex with CUL4B and PSMD11, NRON IncRNA recruits the essential HIV-1 regulatory protein Tat to the ubiquitin/proteasome system and induces its protein degradation. In this scenario, NRON functions as an adaptor between the ubiquitin/protease system and its target protein. We have found that the induced degradation of viral protein by NRON is of specificity, as NRON does not affect the stability of Nef and Vpr proteins. Tat contains several lysine amino-acid residues, and the ubiquitination of K71 enhances its transactivation activity, but not degradation of the protein ${ }^{54}$. The effect of NRON complex-induced Tat ubiquitination therefore could be due to ubiquitination at other lysine residues. More detailed studies are needed to identify the entire molecular mechanism. Further, it is notable that NRON in human has one spliced transcript, whereas three spliced transcripts of NRON have been found in mice. It remains to be determined whether NRON also induced the degradation of other proteins in human or mouse cells. Conversely, the specificity of the NRON-CUL4B/PSMD11 interaction and whether other components of the ubiquitin/proteasome system are involved in this process remains to be determined in future studies. As IncRNA HOTAIR could also be an adaptor between the ubiquitin system and its target proteins Ataxin-1 and Snurportin-1 (ref. 55), it may be interesting to systematically investigate whether other $\operatorname{lncRNAs}$ could mediate the specific degradation of their binding proteins and the molecular mechanisms underlying these processes.

Because of latency, productive viral replication does not occur in resting primary $\mathrm{CD} 4^{+} \mathrm{T}$ lymphocytes of HIV-1-infected individuals receiving suppressive cART. However, replicationcompetent proviral DNA and multiply spliced or unspliced viral RNA can easily be found in these cells ${ }^{56-60}$. The deficiency of Tat protein is the direct consequence of several latency mechanisms such as the deficiency of transcriptional factors such as NF-kB or NFAT, condensed chromatin structure and epigenetic regulation, as well as the enrichment of suppressive cellular microRNAs ${ }^{27,28,30-34}$. It has been well known that the Tat-TAR interaction leads to the recruitment of the pTEFb complex including CDK9/cyclin-T1, which hyperphosphorylates of the C-terminal domain of RNA polymerase II and significantly increases transcription efficiency ${ }^{42-44}$. Recent studies have demonstrated that this positive-feedback regulation strongly controls HIV-1 latency, and Tat induction could robustly activate latently infected viruses ${ }^{61}$. Our work suggests that, by specifically inducing the degradation of Tat protein, NRON at high concentration in the resting $\mathrm{CD} 4^{+} \mathrm{T}$ lymphocytes prevents the accumulation of Tat and therefore acts as a barrier for the transcriptional activation of proviruses. The endogenous NRON expression level in the resting $\mathrm{CD} 4{ }^{+} \mathrm{T}$ lymphocytes of HIV-1-infected individuals is inversely correlated with the intracellular viral RNA expression level, further supporting this hypothesis. Taken together, we propose a novel mechanism contributing to HIV-1 latency maintenance and also a new target for the development of LRAs ${ }^{62}$.

\section{Methods}

Ethics statement. This research was approved by the Ethics Review Board of Sun Yat-Sen University and Guangzhou 8th People's Hospital. Written informed consent was provided by all study participants.

Plasmids and constructs. HIV-1 infectious clone pNL4-3 and its derivative pNL4-3-deltaE-EGFP were obtained through the NIH AIDS Reagent Program, Division of AIDS, NIAID, NIH (refs 37,63). The pHIV-Pro-Luc reporter plasmid was constructed by replacing the CMV promoter of the luciferase gene in the pMIR-REPORT Luciferase vector (Ambion) with the $5^{\prime}$ LTR sequence of HIV $-1_{\text {NL4-3 }}$. Mutations or deletions were introduced into the promoter by PCR-based strategies, and the primer pairs were listed in Supplementary Table 1. The $b c l-2$ gene was chemically synthesized and inserted into the nef region of pNL4-3-deltaE-EGFP provirus plasmid at the XhoI cutting site. Its reading frame is consistent with the nef ORF.

The two exons of HIV-1 full-length tat with an haemagglutinin (HA) epitope tag at its exon-2 $3^{\prime}$ terminus were PCR-amplified from pNL4-3 clone. After connection of two fragments with overlapping PCR, it was inserted into the pcDNA3.1 vector. Human full-length 2,735-bp NRON was amplified using PCR with total cDNA of human peripheral blood mononuclear cells (PBMCs) as the template. Human CULAB and PSMD11 with a FLAG epitope tag sequence at their $3^{\prime}$ terminus was amplified using PCR with total CDNA of human PBMCs as the template. NRON, tagged CUL4B, or PSMD11 were then inserted into the pcDNA3.1 vector. All constructs were verified by DNA sequencing. The $g f p$ coding sequence (CDS) was tagged with HA or FLAG tag at the C terminus and was constructed into the pcDNA3.1 vector ${ }^{64}$. The N-terminus FLAG-tagged human ubiquitin B was constructed into the pcDNA3.1 vector ${ }^{65}$. The renilla luciferaseexpressing plasmid pRL-CMV was obtained from Promega as a transfection normalization reporter for dual-luciferase reporter assay.

Cells and transfection. TZM-bl cells, which harbour an HIV-1 promoter-driven luciferase gene, were obtained from AIDS Reference Reagent Program, NIH. Human HEK293T (American Type Culture Collection (ATCC)), HeLa (ATCC) and TZM-bl cells were maintained in DMEM (Hyclone) supplemented with 10\% fetal bovine serum (Invitrogen), 100 units ml $^{-1}$ of penicillin and $100 \mu \mathrm{g} \mathrm{ml}^{-1}$ of streptomycin at $37^{\circ} \mathrm{C}$. All the cell lines had been tested for mycoplasma using a PCR assay and were mycoplasma-free. The HEK293T, HeLa and TZM-bl cells were transfected using Lipofectamine 2000 (Invitrogen) for plasmids and siRNAs by following the manufacturer's instructions. The cells were collected at $48 \mathrm{~h}$ post transfection for dual-luciferase reporter assays and protein detection. Human primary $\mathrm{CD}^{+}{ }^{+} \mathrm{T}$ lymphocytes were nucleofected with Amaxa Nucleofector using the Amaxa Human T Cell Nucleofector Kit according to the manufacturer's instructions.

Purification of human primary CD4 ${ }^{+} \mathbf{T}$ lymphocytes. The PBMCs were isolated from healthy human donors through Ficoll gradient centrifugation, followed by culturing in the conditioned RPMI 1640 medium. Human primary CD4 ${ }^{+}$ $\mathrm{T}$ lymphocytes were then purified with a human $\mathrm{CD} 4{ }^{+} \mathrm{T}$-cell isolation kit according to the manufacturer's instructions (BD Biosciences). The isolated human primary $\mathrm{CD}^{+} \mathrm{T}$ lymphocytes were then maintained in the conditioned RPMI 1640 medium (Hyclone) and stimulated with phytohaemagglutinin (5 $\mathrm{ng} \mathrm{ml}^{-1}$, Roche Applied Science) and interleukin-2 (IL-2, $10 \mathrm{ng} \mathrm{ml}^{-1}$, R\&D Systems), or anti-CD3 antibody $\left(1 \mu \mathrm{g} \mathrm{ml}^{-1}\right.$, BD Biosciences), anti-CD28 antibody $\left(1 \mu \mathrm{g} \mathrm{ml}^{-1}\right.$, BD Biosciences) and IL-2 (10 $\mathrm{ng} \mathrm{ml}^{-1}$, R\&D Systems) for $48 \mathrm{~h}$. Then, the cells were washed three times with PBS buffer, and were cultured in the presence of IL-2 $\left(10 \mathrm{ng} \mathrm{ml}^{-1}\right)$ 
HIV-1 infection. HEK293T cells at $3 \times 10^{6}$ per dish were plated on 100 -mm cell culture dish. Twenty-four hours later, the cells were transfected with $10 \mu \mathrm{g}$ of pNL4-3 plasmids with Lipofectamine 2000 (Invitrogen) according to the manufacturer's instructions. Cell supernatants were harvested at $48 \mathrm{~h}$ post transfection and were stored at $-80^{\circ} \mathrm{C}$. To normalize viral inputs, the amount of p24 was measured using an HIV-1 p24 ELISA kit according to the manufacturer's instructions (Clonetech). The activated primary $\mathrm{CD} 4{ }^{+} \mathrm{T}$ lymphocytes were seeded into 12 -well cell-culture plates $\left(2 \times 10^{6} \mathrm{ml}^{-1}, 1 \mathrm{ml}\right.$ per well $)$ and were transfected with 200 pmol lncRNA-specific siRNAs or nonspecific control with Lipofectamine RNAiMAX (Invitrogen) according to the manufacturer's instructions. Eight to twelve hours later, the cells were infected with the equivalent of $10 \mathrm{ng}$ HIV-1 p24 antigen per well for $3 \mathrm{~h}$ at $37^{\circ} \mathrm{C}$. Then, the supernatants were removed and the cells were washed three times with fresh PBS buffer. The cells were maintained in the conditioned RPMI 1640 medium supplemented with IL-2 $\left(10 \mathrm{ng} \mathrm{ml}^{-1}\right)$. The culture supernatants were collected on day 7 post infection. For the time-course study of the viral replication, at 7 days post infection, the cells were transfected with NRON siRNAs or nonspecific control for the second time. The culture supernatants were collected at $12 \mathrm{~h}$ (day 0 ), day 3 , day 7 , day 10 or day 14 post infection. All of the culture supernatants were detected using the HIV-1 p24 ELISA kit according to the manufacturer's instructions (Clonetech).

The chemical synthesis of siRNAs. Two or three specific siRNAs for one target lncRNA or protein were pooled together to reduce off-target effects. The chemically synthesized siRNAs and nonspecific control were purchased from RiboBio (Guangzhou). The target sequences of siRNAs were listed in Supplementary Table 2.

Luciferase assay. Twenty-four hours before transfection, HEK293T cells $\left(2 \times 10^{4}\right.$ cells per well) or TZM-bl cells $\left(2.5 \times 10^{4}\right.$ cells per well) were seeded into 48 -well plates. To perform the reporter assay for wild-type or mutated HIV-1 promoter activities, $2 \mathrm{ng}$ of reporter plasmids, $0.2 \mathrm{ng}$ of pRL-CMV and $2 \mathrm{ng}$ of pcDNA3.1Tat-HA were co-transfected with $30 \mathrm{pmol}$ of siRNAs or nonspecific control into HEK293T cells. In all, $1 \mathrm{ng}$ of pRL-CMV, $5 \mathrm{ng}$ of pcDNA3.1-Tat-HA, $40 \mathrm{ng}$ of pcDNA3.1-NRON and/or $30 \mathrm{pmol}$ of siRNAs were co-transfected into TZM-bl cells. To perform the reporter assay for CMV, MMLV or RSV promoter activities, $2 \mathrm{ng}$ of pMIR-Reporter or $10 \mathrm{ng}$ of MMLV or RSV promoter reporter plasmids were transfected with $30 \mathrm{pmol}$ of siRNAs or nonspecific control into HEK293T cells. Human primary $\mathrm{CD} 4^{+} \mathrm{T}$ lymphocytes $\left(3-5 \times 10^{6}\right.$ cells per well) from healthy donors were nucleofected with $2 \mu \mathrm{g}$ of HIV-1 promoter reporter plasmid, $200 \mathrm{ng}$ of pRL-CMV, $2 \mu \mathrm{g}$ of pcDNA3.1-Tat-HA and $100 \mathrm{pmol}$ of siRNAs. Dual-luciferase reporter assay was performed at $48 \mathrm{~h}$ post transfection using the Promega Dual-Luciferase Reporter Assay System according to the manufacturer's instructions ${ }^{66,67}$

RNA isolation and real-time qRT-PCR. RNA was isolated with TRIZOL reagent according to the manufacturer's instructions (Ambion), and was treated with RQ-1 DNase (Promega) before reverse transcription. Reverse transcription reactions were performed with the PrimeScript RT reagent Kit (TaKaRa). Quantitative PCR was performed with the SYBR Premix ExTaq Kit (TaKaRa) on a CFX96 Real-Time System (Bio-Rad) by following the manufacturer's instructions. Primers for real-time qRT-PCR were listed in Supplementary Table 3. Human glyceraldehyde3-phosphate dehydrogenase (GAPDH) or $\beta$-actin mRNA was measured as endogenous controls. For RIP-qPCRs, the amount of a target RNA was normalized to $10 \%$ total input sample RNA level in each RIP sample and was represented as percentage relative to input sample using the delta Ct method ${ }^{68}$.

Co-IP and western blotting. HEK293T cells at $1.2 \times 10^{6}$ per dish were plated onto $60-\mathrm{mm}$ cell culture dish. Twenty-four hours later, the cells were transfected with $1 \mu \mathrm{g}$ of pcDNA3.1-Tat-HA and/or $0.8 \mu \mathrm{g}$ of pcDNA3.1-CUL4B-FLAG or pcDNA3.1-PSMD11-FLAG. The cells were co-transfected with 400 pmol of specific or control siRNAs when needed. Alternatively, $1.5 \times 10^{6} \mathrm{TZM}-\mathrm{bl}$ cells were plated onto $60-\mathrm{mm}$ cell culture dish. Twenty-four hours later, the cells were transfected with $1 \mu \mathrm{g}$ of pcDNA3.1-NRON, $1.5 \mu \mathrm{g}$ of pcDNA3.1-Tat-HA and/or $1 \mu \mathrm{g}$ of pcDNA3.1-CUL4B-FLAG or pcDNA3.1-PSMD11-FLAG. Cells were co-transfected with $400 \mathrm{pmol}$ of specific or control siRNAs when needed. At $48 \mathrm{~h}$ post transfection, cells were collected and disrupted with RIPA lysis buffer $(150 \mathrm{mM} \mathrm{NaCl}$, $50 \mathrm{mM}$ Tris- $\mathrm{HCl}$ (pH 7.5), $1 \mathrm{mM}$ EDTA, $1 \% \mathrm{NP} 40$ and $0.5 \%$ Triton X-100) containing protease inhibitor cocktail (Sigma) and RNaseOut (Invitrogen) for $30 \mathrm{~min}$ on ice. The cell lysates were clarified with centrifugation at $12,000 \mathrm{~g}$ for $10 \mathrm{~min}$ at $4{ }^{\circ} \mathrm{C}$. The supernatants were pre-cleared with agarose beads, and then mixed with anti-HA beads (Sigma A2095) or anti-FLAG beads (Sigma F2426) and incubated at $4{ }^{\circ} \mathrm{C}$ for $4 \mathrm{~h}$ to overnight. The beads were washed five times with cold lysis buffer at $4^{\circ} \mathrm{C}$. RNase A was added to wash buffer $\left(20 \mathrm{ug} \mathrm{ml}^{-1}\right)$ when needed. RNA isolation followed by real-time GRT-PCR, or western blotting, was then performed ${ }^{67}$. The anti-HA antibody (1:2,000 diluted, mouse monoclonal, MBL International Corporation, M180-3), anti-FALG antibody (1:1,000 diluted, rabbit polyclonal, MBL International Corporation, PM020), anti- $\beta$-actin antibody (1:1,000 diluted, rabbit polyclonal, CST \#4967), anti-GAPDH antibody (1:5,000 diluted, rabbit polyclonal, Proteintech Group, 10494-1-AP) or anti-p24 antibody
(1:500 diluted $)^{64}$ were used as the primary antibodies. Images were analysed using the Quantity One Software (Bio-Rad). The uncropped scans of the most important blots were supplied in Supplementary Fig. 6.

In vitro ubiquitin assay. HEK293T cells at $1.2 \times 10^{6}$ per dish were plated onto 60-mm cell culture dish. Twenty-four hours later, the cells were transfected with $1 \mu \mathrm{g}$ of pcDNA3.1-Tat-HA, $2 \mu \mathrm{g}$ of pcDNA3.1-Flag-Ub or empty pcDNA3.1 vector, and 400 pmol of specific or control siRNAs. MG132 $(5 \mu \mathrm{M})$ was added into the cultures $12 \mathrm{~h}$ before the cells were harvested. At $48 \mathrm{~h}$ post transfection, cells were collected and disrupted by lysis buffer for anti-HA immunoprecipitation. Western blot analysis was then performed with anti-HA or anti-FLAG primary antibodies.

Northern blotting. For NRON IncRNA detection, $20 \mu \mathrm{g}$ of total RNA was separated by $1.2 \%$ formaldehyde-denature agarose gel, and then transferred to Amersham Hybond- $\mathrm{N}^{+}$membrane (GE Healthcare) and ultraviolet-crosslinked RNA to the membrane. The membrane was prehybridized with salmon sperm DNA $\left(100 \mu \mathrm{g} \mathrm{ml}^{-1}\right.$, Sigma), and was hybridized with NRON and Actin-specific probes. Then, the membrane was washed three times, dried, exposed on a phosphorimager screen (GE Healthcare) and scanned on a laser scanner (GE Healthcare) ${ }^{69}$. The reverse primers of NRON and Actin for real-time qRT-PCR were used as oligonucleotide probes, and were labelled with $\alpha_{-}{ }^{32} \mathrm{P}$ (PerkinElmer) by T4 polynucleotide kinase (NEB).

HIV in vitro latency model. The HIV-1/VSV-pseudotyped viruses were packaged in HEK293T cells by co-transfecting pNL4-3-deltaE-EGFP-Bcl-2 and pVSV-G. The activated primary $\mathrm{CD} 4^{+} \mathrm{T}$ lymphocytes isolated from healthy individuals were infected with the pseudotyped viruses, and the GFP-positive cells were sorted out by FACS and expanded by culturing in the conditioned RPMI 1640 medium containing anti-CD3 antibody ( $1 \mu \mathrm{g} \mathrm{ml}^{-1}, \mathrm{BD}$ Biosciences), anti-CD28 antibody $\left(1 \mu \mathrm{g} \mathrm{ml}^{-1}, \mathrm{BD}\right.$ Biosciences) and IL-2 (10 $\mathrm{ng} \mathrm{ml}^{-1}, \mathrm{R} \& \mathrm{D}$ Systems) for 7 days. The cells were cultured for $\sim 4$ weeks with low concentration of IL-2 $\left(2 \mathrm{ng} \mathrm{ml}^{-1} \mathrm{R} \& \mathrm{D}\right.$ Systems), and then the GFP-negative cells were enriched by FACS and subjected to activation by various reagents.

HIV-1-infected individual samples. The HIV-1-infected individuals with the blood plasma viral RNA less than 20 copies per $\mathrm{ml}$ and the number of $\mathrm{CD}_{4}^{+}$ lymphocytes higher than $200 \mu \mathrm{l}^{-1}$ were recruited for our study. The PBMCs were isolated through Ficoll gradient centrifugation, followed by culture in the conditioned RPMI 1640 medium. For NRON knockdown assay, the integrated HIV-1 proviruses in the resting $\mathrm{CD} 4{ }^{+} \mathrm{T}$ lymphocytes were confirmed with Alu-PCR ${ }^{34}$. The resting $\mathrm{CD}^{+}{ }^{+} \mathrm{T}$ lymphocytes were transfected with siRNAs $(200 \mathrm{nM})$ and treated in combination with SAHA $(300 \mathrm{nM})$, or with anti-CD3 antibody, anti-CD28 antibody and IL-2 as positive controls. Viral RNAs in culture supernatant were isolated and detected by real-time $\mathrm{qRT}-\mathrm{PCR}$ at $48 \mathrm{~h}$ after transfection $^{34}$. For intracellular RNA expression and proviral DNA detection, total RNA and DNA were directly isolated from the primary resting $\mathrm{CD} 4{ }^{+}$ T lymphocytes. HIV-1 viral RNA and NRON RNA expression levels were detected with real-time $\mathrm{qRT}-\mathrm{PCR}$, and then normalized to the endogenous control $\beta$-actin mRNA using the delta $\mathrm{Ct}$ method ${ }^{34}$. The integrated proviral DNA levels were detected using real-time PCR with a primer set targeting Gag ORF ${ }^{34,56}$, and then normalized to $\beta$-actin DNA using the delta Ct method ${ }^{68}$

Statistical analysis. Results of the experiments were presented as mean \pm s.d. (error bars). Student's unpaired $t$-test was used to determine significance. ${ }^{*} P<0.05$ and ${ }^{* *} P<0.01$ indicated significant difference. Correlation analysis was determined using a simple linear regression analysis in the SPSS software.

Data availability. The data that support the findings of this study are available from the corresponding author upon request.

\section{References}

1. Ulitsky, I. \& Bartel, D. P. lincRNAs: genomics, evolution, and mechanisms. Cell 154, 26-46 (2013).

2. Carninci, P. et al. The transcriptional landscape of the mammalian genome. Science 309, 1559-1563 (2005).

3. Guttman, M. et al. Chromatin signature reveals over a thousand highly conserved large non-coding RNAs in mammals. Nature 458, 223-227 (2009).

4. Ponjavic, J., Ponting, C. P. \& Lunter, G. Functionality or transcriptional noise? Evidence for selection within long noncoding RNAs. Genome Res. 17, 556-565 (2007).

5. Khalil, A. M. et al. Many human large intergenic noncoding RNAs associate with chromatin-modifying complexes and affect gene expression. Proc. Natl Acad. Sci. USA 106, 11667-11672 (2009).

6. Tuck, A. C. \& Tollervey, D. A transcriptome-wide atlas of RNP composition reveals diverse classes of mRNAs and IncRNAs. Cell 154, 996-1009 (2013). 
7. Rinn, J. L. et al. Functional demarcation of active and silent chromatin domains in human HOX loci by noncoding RNAs. Cell 129, 1311-1323 (2007).

8. Nagano, T. et al. The Air noncoding RNA epigenetically silences transcription by targeting G9a to chromatin. Science 322, 1717-1720 (2008)

9. Gupta, R. A. et al. Long non-coding RNA HOTAIR reprograms chromatin state to promote cancer metastasis. Nature 464, 1071-1076 (2010)

10. Yang, L. et al. ncRNA- and Pc2 methylation-dependent gene relocation between nuclear structures mediates gene activation programs. Cell 147, 773-788 (2011)

11. Huarte, M. et al. A large intergenic noncoding RNA induced by p53 mediates global gene repression in the p53 response. Cell 142, 409-419 (2010).

12. Orom, U. A. et al. Long noncoding RNAs with enhancer-like function in human cells. Cell 143, 46-58 (2010).

13. Cesana, M. et al. A long noncoding RNA controls muscle differentiation by functioning as a competing endogenous RNA. Cell 147, 358-369 (2011).

14. Tay, Y. et al. Coding-independent regulation of the tumor suppressor PTEN by competing endogenous mRNAs. Cell 147, 344-357 (2011).

15. Gong, C. \& Maquat, L. E. IncRNAs transactivate STAU1-mediated mRNA decay by duplexing with 3' UTRs via Alu elements. Nature 470, 284-288 (2011).

16. Carrieri, C. et al. Long non-coding antisense RNA controls Uchl1 translation through an embedded SINEB2 repeat. Nature 491, 454-457 (2012).

17. Kino, T., Hurt, D. E., Ichijo, T., Nader, N. \& Chrousos, G. P. Noncoding RNA gas5 is a growth arrest- and starvation-associated repressor of the glucocorticoid receptor. Sci. Signal. 3, ra8 (2010).

18. Willingham, A. T. et al. A strategy for probing the function of noncoding RNAs finds a repressor of NFAT. Science 309, 1570-1573 (2005).

19. Geisler, S. \& Coller, J. RNA in unexpected places: long non-coding RNA functions in diverse cellular contexts. Nat. Rev. Mol. Cell Biol. 14, 699-712 (2013).

20. Loewer, S. et al. Large intergenic non-coding RNA-RoR modulates reprogramming of human induced pluripotent stem cells. Nat. Genet. 42, 1113-1117 (2010).

21. Carpenter, S. et al. A long noncoding RNA mediates both activation and repression of immune response genes. Science 341, 789-792 (2013).

22. Gomez, J. A. et al. The NeST long ncRNA controls microbial susceptibility and epigenetic activation of the interferon-gamma locus. Cell 152, 743-754 (2013).

23. Batista, P. J. \& Chang, H. Y. Long noncoding RNAs: cellular address codes in development and disease. Cell 152, 1298-1307 (2013).

24. Finzi, D. et al. Identification of a reservoir for HIV-1 in patients on highly active antiretroviral therapy. Science 278, 1295-1300 (1997).

25. Wong, J. K. et al. Recovery of replication-competent HIV despite prolonged suppression of plasma viremia. Science 278, 1291-1295 (1997).

26. Chun, T. W. et al. Presence of an inducible HIV-1 latent reservoir during highly active antiretroviral therapy. Proc. Natl Acad. Sci. USA 94, 13193-13197 (1997).

27. Nabel, G. \& Baltimore, D. An inducible transcription factor activates expression of human immunodeficiency virus in T cells. Nature 326, 711-713 (1987)

28. Kinoshita, S., Chen, B. K., Kaneshima, H. \& Nolan, G. P. Host control of HIV-1 parasitism in T cells by the nuclear factor of activated T cells. Cell 95, 595-604 (1998).

29. Kao, S. Y., Calman, A. F., Luciw, P. A. \& Peterlin, B. M. Anti-termination of transcription within the long terminal repeat of HIV-1 by tat gene product. Nature 330, 489-493 (1987).

30. Coull, J. J. et al. The human factors YY1 and LSF repress the human immunodeficiency virus type 1 long terminal repeat via recruitment of histone deacetylase 1. J. Virol. 74, 6790-6799 (2000).

31. Williams, S. A. et al. NF-kappaB p50 promotes HIV latency through HDAC recruitment and repression of transcriptional initiation. EMBO J. 25, 139-149 (2006).

32. du Chene, I. et al. Suv39H1 and HP1gamma are responsible for chromatinmediated HIV-1 transcriptional silencing and post-integration latency. EMBO J. 26, 424-435 (2007)

33. Kauder, S. E., Bosque, A., Lindqvist, A., Planelles, V. \& Verdin, E. Epigenetic regulation of HIV-1 latency by cytosine methylation. PLoS Pathog. 5, e1000495 (2009).

34. Huang, J. et al. Cellular microRNAs contribute to HIV-1 latency in resting primary CD4 ${ }^{+}$T lymphocytes. Nat. Med. 13, 1241-1247 (2007).

35. Gibb, E. A. et al. Human cancer long non-coding RNA transcriptomes. PLoS ONE 6, e25915 (2011).

36. Szabo, S. J. et al. A novel transcription factor, T-bet, directs Th1 lineage commitment. Cell 100, 655-669 (2000).

37. Zhang, H. et al. Novel single-cell-level phenotypic assay for residual drug susceptibility and reduced replication capacity of drug-resistant human immunodeficiency virus type 1. J. Virol. 78, 1718-1729 (2004).

38. Kinoshita, S. et al. The T cell activation factor NF-ATc positively regulates HIV-1 replication and gene expression in T cells. Immunity 6, 235-244 (1997).

39. Cron, R. Q. et al. NFAT1 enhances HIV-1 gene expression in primary human CD4 T cells. Clin. Immunol. 94, 179-191 (2000).
40. Romanchikova, N. et al. NFAT transcription factors control HIV-1 expression through a binding site downstream of TAR region. Immunobiology 208, 361-365 (2003).

41. Pereira, L. A., Bentley, K., Peeters, A., Churchill, M. J. \& Deacon, N. J. A compilation of cellular transcription factor interactions with the HIV-1 LTR promoter. Nucleic Acids Res. 28, 663-668 (2000).

42. Wei, P., Garber, M. E., Fang, S. M., Fischer, W. H. \& Jones, K. A. A novel CDK9-associated C-type cyclin interacts directly with HIV-1 Tat and mediates its high-affinity, loop-specific binding to TAR RNA. Cell 92, 451-462 (1998).

43. Zhu, Y. et al. Transcription elongation factor P-TEFb is required for HIV-1 tat transactivation in vitro. Genes Dev. 11, 2622-2632 (1997).

44. Parada, C. A. \& Roeder, R. G. Enhanced processivity of RNA polymerase II triggered by Tat-induced phosphorylation of its carboxy-terminal domain. Nature 384, 375-378 (1996).

45. Roy, S., Delling, U., Chen, C. H., Rosen, C. A. \& Sonenberg, N. A bulge structure in HIV-1 TAR RNA is required for Tat binding and Tat-mediated trans-activation. Genes Dev. 4, 1365-1373 (1990).

46. Cordingley, M. G. et al. Sequence-specific interaction of Tat protein and Tat peptides with the transactivation-responsive sequence element of human immunodeficiency virus type 1 in vitro. Proc. Natl Acad. Sci. USA 87, 8985-8989 (1990).

47. Dingwall, C. et al. HIV-1 tat protein stimulates transcription by binding to a U-rich bulge in the stem of the TAR RNA structure. EMBO J. 9, 4145-4153 (1990).

48. Yang, H. C. et al. Small-molecule screening using a human primary cell model of HIV latency identifies compounds that reverse latency without cellular activation. J. Clin. Invest. 119, 3473-3486 (2009).

49. Bosque, A. \& Planelles, V. Induction of HIV-1 latency and reactivation in primary memory CD4 ${ }^{+}$T cells. Blood 113, 58-65 (2009).

50. Contreras, X. et al. Suberoylanilide hydroxamic acid reactivates HIV from latently infected cells. J. Biol. Chem. 284, 6782-6789 (2009).

51. Zhang, Q., Chen, C. Y., Yedavalli, V. S. \& Jeang, K. T. NEAT1 long noncoding RNA and paraspeckle bodies modulate $\mathrm{HIV}-1$ posttranscriptional expression. MBio 4, e00596-e00512 (2013).

52. Liu, Z. et al. The kinase LRRK2 is a regulator of the transcription factor NFAT that modulates the severity of inflammatory bowel disease. Nat. Immunol. 12, 1063-1070 (2011).

53. Imam, H., Bano, A. S., Patel, P., Holla, P. \& Jameel, S. The lncRNA NRON modulates HIV-1 replication in a NFAT-dependent manner and is differentially regulated by early and late viral proteins. Sci. Rep. 5, 8639 (2015).

54. Bres, V. et al. A non-proteolytic role for ubiquitin in Tat-mediated transactivation of the HIV-1 promoter. Nat. Cell Biol. 5, 754-761 (2003).

55. Yoon, J. H. et al. Scaffold function of long non-coding RNA HOTAIR in protein ubiquitination. Nat. Commun. 4, 2939 (2013).

56. Ho, Y. C. et al. Replication-competent noninduced proviruses in the latent reservoir increase barrier to HIV-1 cure. Cell 155, 540-551 (2013).

57. Furtado, M. R. et al. Persistence of HIV-1 transcription in peripheral-blood mononuclear cells in patients receiving potent antiretroviral therapy. N. Engl. J Med. 340, 1614-1622 (1999).

58. Chun, T. W. et al. Gene expression and viral prodution in latently infected, resting $\mathrm{CD}^{+}{ }^{+} \mathrm{T}$ cells in viremic versus aviremic HIV-infected individuals. Proc. Natl Acad. Sci. USA 100, 1908-1913 (2003).

59. Lassen, K. G., Ramyar, K. X., Bailey, J. R., Zhou, Y. \& Siliciano, R. F. Nuclear retention of multiply spliced HIV-1 RNA in resting $\mathrm{CD}^{+}{ }^{+} \mathrm{T}$ cells. PLoS Pathog. 2, e68 (2006).

60. Zhang, L. et al. Quantifying residual HIV-1 replication in patients receiving combination antiretroviral therapy. N. Engl. J. Med. 340, 1605-1613 (1999).

61. Razooky, B. S., Pai, A., Aull, K., Rouzine, I. M. \& Weinberger, L. S. A hardwired HIV latency program. Cell 160, 990-1001 (2015).

62. Bullen, C. K., Laird, G. M., Durand, C. M., Siliciano, J. D. \& Siliciano, R. F. New ex vivo approaches distinguish effective and ineffective single agents for reversing HIV-1 latency in vivo. Nat. Med. 20, 425-429 (2014).

63. Adachi, A. et al. Production of acquired immunodeficiency syndromeassociated retrovirus in human and nonhuman cells transfected with an infectious molecular clone. J. Virol. 59, 284-291 (1986).

64. Zhou, X. et al. DDX5 facilitates HIV-1 replication as a cellular co-factor of Rev. PLoS ONE 8, e65040 (2013).

65. Kamitani, T., Kito, K., Nguyen, H. P. \& Yeh, E. T. Characterization of NEDD8, a developmentally down-regulated ubiquitin-like protein. J. Biol. Chem. 272, 28557-28562 (1997).

66. Chen, K. et al. Alpha interferon potently enhances the anti-human immunodeficiency virus type 1 activity of APOBEC3G in resting primary CD4 T cells. J. Virol. 80, 7645-7657 (2006).

67. Liu, C. et al. APOBEC3G inhibits microRNA-mediated repression of translation by interfering with the interaction between Argonaute- 2 and MOV10. J. Biol. Chem. 287, 29373-29383 (2012) 
68. Livak, K. J. \& Schmittgen, T. D. Analysis of relative gene expression data using real-time quantitative PCR and the 2(-Delta Delta C(T)) Method. Methods 25, 402-408 (2001).

69. Streit, S., Michalski, C. W., Erkan, M., Kleeff, J. \& Friess, H. Northern blot analysis for detection and quantification of RNA in pancreatic cancer cells and tissues. Nat. Protoc. 4, 37-43 (2009).

\section{Acknowledgements}

We obtained the HIV-1 provirus plasmid pNL4-3-deltaE-EGFP that was constructed in the laboratory of Dr Robert Siliciano from the National Institutes of Health AIDS Reagent Program. This work was funded by National Special Research Program of China for Important Infectious Diseases (No.2013ZX10001004), National Science and Technology Major Project (No.2012ZX10001003-004-002), Guangdong Innovative Research Team Program (No.2009010058), the National Natural Science Foundation of China (NSFC-NIH project) (No.81561128007) and the Joint-innovation Program in Healthcare for Special Scientific Research Projects of Guangzhou, China (201508020256) to H.Z.

\section{Author contributions}

J.L. designed and performed the most experiments and analyses; C.C. and G.G. participated in generating the in vitro latency model; C.C. and X.M. contributed to some plasmid constructing, real-time $\mathrm{qRT}-\mathrm{PCR}$ and western blotting experiments.
Y.Z., B.L., S.Z., F.Z., C.L. and Y.Y. participated in some experiments. W.P.C. recruited the HIV-1-infected individuals. H.Z. directed and supervised the project and interpretation of data. J.L. and H.Z. prepared the manuscript.

\section{Additional information}

Supplementary Information accompanies this paper at http://www.nature.com/ naturecommunications

Competing financial interests: The authors declare no competing financial interests.

Reprints and permission information is available online at http://npg.nature.com/ reprintsandpermissions/

How to cite this article: Li, J. et al. Long noncoding RNA NRON contributes to HIV-1 latency by specifically inducing tat protein degradation. Nat. Commun. 7:11730 doi: $10.1038 /$ ncomms11730 (2016).

\section{(c) (1)}

This work is licensed under a Creative Commons Attribution 4.0 International License. The images or other third party material in this article are included in the article's Creative Commons license, unless indicated otherwise in the credit line; if the material is not included under the Creative Commons license, users will need to obtain permission from the license holder to reproduce the material. To view a copy of this license, visit http://creativecommons.org/licenses/by/4.0/ 